\title{
Policy insights and modelling challenges: The case of passenger car powertrain technology transition in the European Union
}

\author{
Gillian Harrison $^{1}$ (D) Christian Thiel $^{1}$
}

Received: 11 October 2016 / Accepted: 19 June 2017 / Published online: 5 July 2017

(C) The Author(s) 2017. This article is an open access publication

\begin{abstract}
Purpose We are interested in what policy insights can be transferred from EU countries that have been most successful in introducing EVs to those that are debating policy options. As we use a model to explore this, we are also interested in the application of modelling, seeking to understand if real world policies and results can be replicated in a model and, more generally, the challenges to the use of modelling in policy appraisal.

Methods We use the EC-JRC Powertrain Technology Transition Market Agent Model (PTTMAM), a system dynamics model based around the interactions of conceptual market agent groups in the EU. We perform iterative scenario tests to replicate the policies carried out in the Netherlands and the UK in recent years in an attempt to achieve similar results in EV sales. We then transfer the policy scenarios to other EU member states and assess the transferability of the policies.

Results Reasonable approximations of the Netherlands and UK EV policies and sales were achieved and implemented in other EU member states.

Conclusion We find that the PTTMAM is fit-for-purpose and can replicate successful policies to a certain degree. Policy success is sensitive to country specific conditions, and a
\end{abstract}

The views expressed are purely those of the authors and may not in any circumstances be regarded as stating an official position of the European Commission

Gillian Harrison

drgillianharrison@gmail.com

1 European Commission, Joint Research Centre, Directorate for Energy, Transport and Climate, Via Enrico Fermi 2749, I-21027 Ispra, VA, Italy system dynamics model like the PTTMAM can help identify which conditions react to which policy stimulus. There are challenges to modelling in policy appraisal, such as the subjectivity of the modeller and flexibility to specific conditions, which must be kept transparent for the model to be a relevant tool for policy making.

Keywords Electro-mobility · Policy Design · Transport . System Dynamics Modelling $\cdot$ EU

\section{Introduction}

As part of the White Paper on Transport [1] there is the desire to significantly reduce emissions from road transport vehicles, and to eliminate all tailpipe emissions from urban areas. The European Union (EU) has introduced numerous regulations in support of this goal, including fleet emission targets [2-5] and the Alternative Fuel Infrastructure Directive [6]. The transition away from conventionally fuelled internal combustion engine vehicles towards electric vehicles (EV) forms a major part of this. Therefore a comprehensive system dynamics model of the EU light duty vehicle road transport sector was built, in order to satisfy a need to create a more sophisticated model for understanding relevant interactions and transitions than previously available. This model, the Powertrain Technology Transition Market Agent Model (PTTMAM) has been presented in previous publications [7-9]. In this paper, modelling case studies are tested against "real-world" passenger car Plug-in Electric Vehicle (PiEV) uptake. PiEV are a subcategory of EV that includes only Battery Electric Vehicle (BEV) and Plug-in Hybrid Electric Vehicle (PHEV). Due to the timescale of this paper Fuel Cell Vehicles are not directly considered. This exercise addresses three research questions: 1) Can the model replicate short term effects of real world 
policies in individual countries?; 2) What policy insights can be transferred from EU countries who have been successful in introducing EVs to others that are debating policy options?; and 3) What challenges are there to the use of modelling in policy appraisal? Question 1 relates to an extension in scope of a model that is primarily geared to analyse longer term effects of policies and market developments, and has to date only been used in studies at an EU-wide level. Question 2 is important for evidence-based policy advice that can inform future policy decisions by both the EU and individual member states. Question 3 addresses the need to qualify the model based conclusions within the context of the limitations of the chosen modelling approach.

\section{Background}

As discussed in previous literature [10,11], the use of system dynamics modelling is widespread in transport studies, and in particular regarding the uptake of new and alternative fuel vehicle (AFV) technologies. Without wishing to repeat the review or discussion of previous papers, suffice to say that to date, many of these models and studies have been limited in their scope. Due to the nature of modelling a detailed focus on a specific area, with assumptions regarding aspects external to the study boundaries, is a necessity For example, system dynamics has been used to model specific regulations on automobile manufacturers in California [12], the concept of 'willingness to consider' a generic AFV [13], strategic niche management of AFVs [14], and the impact of infrastructure on potential hydrogen transitions in Germany [15]. However, in order to support the European Commission in their policy decisions a model that expanded on these studies was required, which can consider multiple countries, market agents and alternative technologies relevant to the complex market that exists within the EU.

The EV market is still in its early stages in Europe [16]. EU member states are adopting various strategies to encourage the take up of new technologies, concerning both the vehicle and its supportive infrastructure. In this study the Powertrain Technology Transition Market Agent Model (PTTMAM), a system dynamics model implemented in Vensim ${ }^{\mathrm{TM}}$ software, is employed to generate policy insights that could support both EU-wide regulations and the implementation of policy in individual member states. Studies using the PTTMAM have been published that consider the impact of key market and policy conditions [9], and the sensitivity to infrastructure [7]. This study builds on these publications that have only considered hypothetical scenarios at an EU level.

In this paper, following a short model introduction that summarises a publically available Technical Report describing the PTTMAM [8], the responsiveness of the model to reallife policies is established, using the Netherlands and UK as case studies. As the EV market remains in infancy and extensive data and experience is simply not available, the model is calibrated to historical data for key parameters such as vehicle demand and component costs. At present it is difficult to capture some of the more detailed dynamics within the system or to fully replicate individual or focused (eg regional or user oriented) policies. As such, it is necessary to manually perform iterative testing of simplified policy representations to obtain model scenarios that reasonably match reality. This learning is then applied across the whole EU and discussion focuses in particular on those EU member states with less ambitious EV policies to understand if a similar success could be achieved if the case study policies were applied. The paper concludes with a summary of the policy insights and modelling challenges encountered in the study.

\section{Model Description}

The PTTMAM was initially designed around the decision rules and main interactions of four conceptual market agent groups, being Users, Manufacturers, Infrastructure Providers and Authorities, fundamentally similar to [12]. The aim is to study the interaction between, and influence of, the market agents of the automobile sector on possible powertrain technology transitions within Europe, for each of the member states, and across the period 1995 to 2050. It has been in use since 2013, and has undergone continuous improvements and updates as new data and concepts become available. The model is not agent-based, i.e. it does not consider actions at an individual level for any of the conceptual groups. Nevertheless, through subscripting (such as powertrain type or member state) the model does allow the disaggregation of the conceptual groups into sub-groups in order to distinguish some behavioural variations. As would be expected, boundaries and assumptions had to be imposed in order to simplify the model. For instance, the model only represents in detail the $28 \mathrm{EU}$ member states, with all other countries accounted for as rest of the world simplifications, and only where their interactions would appear to be relevant. Where reliable data was available it was used as an exogenous input or calibration dataset, otherwise expert judgment was employed. The main sources of this data include [17-19] and various industry associations, such as the European Automobile Manufacturers Association (ACEA). Endogenous variables were defined by standard formulations or sourced from literature, such as [13, 20]. In a model scenario, the user may alter data inputs or model structure to represent market conditions, implemented policies or manufacturer/infrastructure provider strategies. The simulation performs calculation for every 0.25 /year between 1995 and 2050, though in our work we only consider annual figures. Fig. 1 is a high-level overview diagram of the PTTMAM, representing the key interactions and feedbacks 


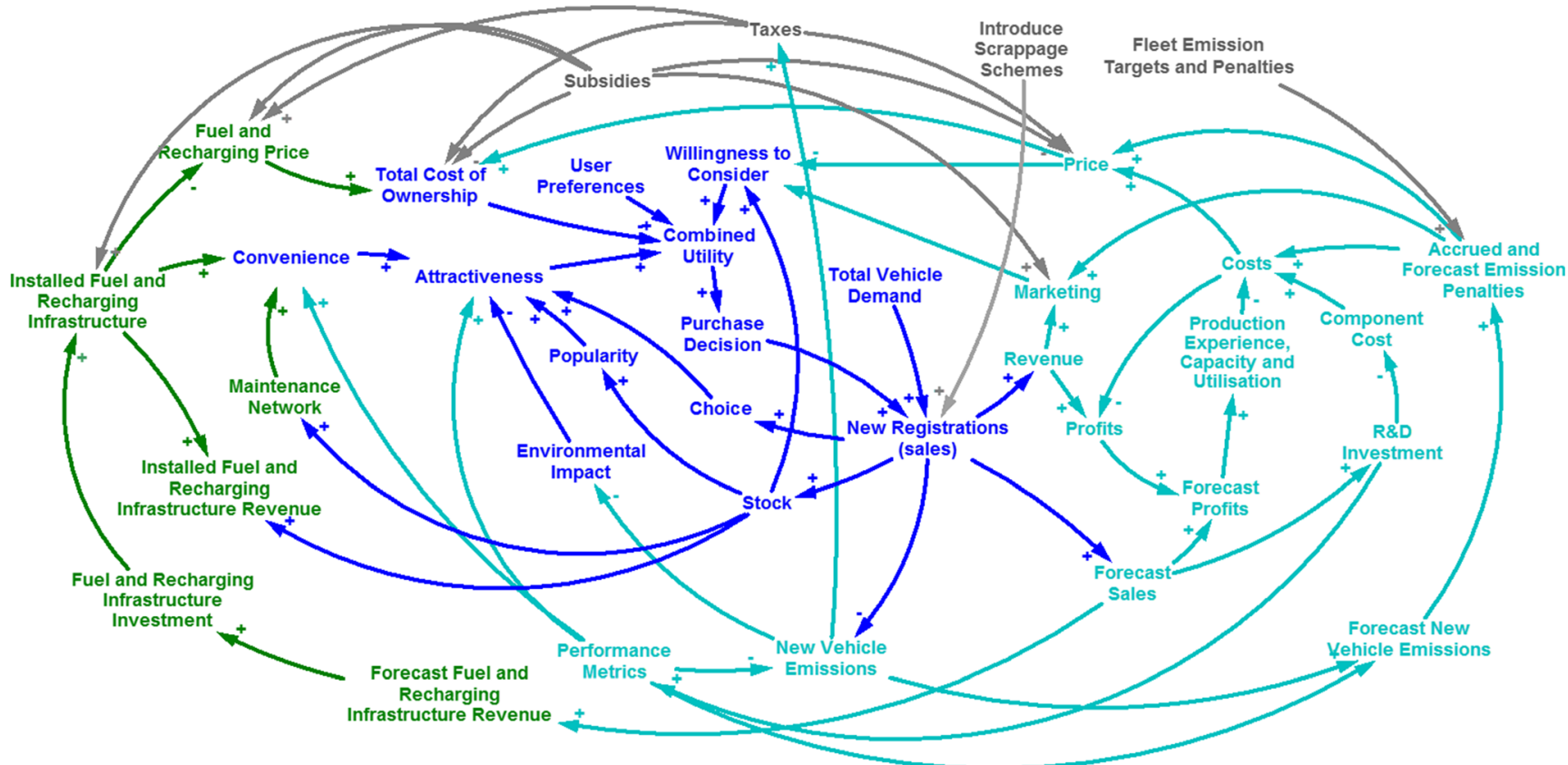

Fig. 1 High-level overview (NOT a causal loop diagram, but showing polarity of relationships) of PTTMAM main interactions (Colours represent market agent group: Blue $=$ Users, Green $=$ Infrastructure
Providers, Turquoise $=$ Manufacturers, Grey $=$ Authorities $)($ From Technical Report and adapted from Pasaoglu et al. [9])) between the four market agents. In reality, the full model contains over 1300 separate variables, leading to more than 550,000 once subscripts are considered. Of this, there are over 300 data variables (nearly 12,000 inputs when including subscripts) and 18 data look-up tables. Due to this high data dependence, the model was subjected to robust validation testing, which is described in more detail in the model Technical Report [8]. Most importantly, for 71 key data inputs that could not be reliably obtained, calibrations were carried out using historical data sets. These inputs are updated periodically when sufficient new data becomes available. Furthermore, sensitivity analyses of 146 data inputs were carried out to assess the impact on key performance indicators EV sales and Emissions to determine confidence in the chosen input values for the model baseline. For further assessment and validation of the logic of the model structure and outputs, reality checks and extreme cases were tested to assess if the model responded appropriately and assist in the design of baseline scenarios (see Technical Report (ibid.) for further detail on these). The successful adherence to these checks supports confidence in the interpretation of any observed behaviour, despite the high degree of freedom and uncertainty in a large model. Further to this an external expert reviewed and verified the technical report and model. Relevant to this study, the reader should note that a number of parameters are calibrated at a country level to historical data sets from the period 1995-2013, for example the coefficients that determine total vehicle stock and demand, sensitivity to scrappage schemes, willingness to consider powertrains, infrastructure fuel margins, and vehicle emissions. Fractional sales and stock are one of the historical data sets used for this, but as EVs are new technologies, reliable data was only available for sales in limited countries from 2010. In addition, due to the time frame of the calibration, no policies were used in the calibration of the baseline, so it may be seen as a reference against which to assess the impact of policies as we do in this study.

The previously mentioned Technical Report describes the model in detail, including model structure, key equations and data inputs, by market agent group. The main characteristics and decision rules of the groups are further summarised in Pasaoglu et al. [9]. Nonetheless, for the reader we provide here a brief overview of the key aspects and interactions which drive the model.

\subsection{Users}

The user group (blue variables of Fig. 1) is responsible for the evaluation and purchase of new vehicles at each time step of the simulation. Overall vehicle demand is determined by internally calibrated variables for each member state. Vehicle stock market share is thus governed by the inflow of new registrations and outflow of discarded vehicles (eg from aging or unaffordability). Within the demand, market shares for each powertrain type, size, and user group (eg urban/non-urban or public/private/fleet) are determined using a simple multinomial logit discrete choice model based on a combined utility of each powertrain. The attributes that characterise the powertrains, and drive their attractiveness are Environment, 
Performance, Reliability, Safety, Convenience, Popularity, and Choice. They evolve in relation to the investment in research \& development (R\&D) and infrastructure. Also included in the combined utility is a 'willingness to consider' concept [13], and a relative financial cost (purchase price and a proportion of running costs). In future development the choice model will be further refined to obtain more specific preference parameters and a cross-nested structure. User choice is further influenced by the other market agent groups - authorities as they introduce subsidies or scrappage schemes, infrastructure providers who build infrastructure, and manufacturers investing in $\mathrm{R} \& \mathrm{D}$ of the new technologies.

\subsection{Manufacturers}

Within the PTTMAM, automobile manufacturers (turquoise variables of Fig. 1) are considered as a whole, rather than as individual manufacturers, though there is a certain amount of competitiveness built in to capture these important behaviours. They are responsible for the development, production, pricing and marketing of all vehicles. Influences from the authorities, such as fleet emission targets, and from users who take up new technologies, drive the decisions by manufacturers to invest in production capacity and $R \& D$ of new technologies, due to forecast or speculative profits. As such, R\&D, Financials and Production form the basis of this agent group. This results in a large number of variables, data inputs (and calibrations) for this section of the model. Although the PTTMAM is focused on Europe, assumptions are made regarding importing and exporting of vehicles to the rest of the world. Manufacturers influence sales of new technologies by their pricing and marketing decisions, in addition to improvements in vehicle attributes brought about by $R \& D$ investment. This module includes an assessment of future profits, current maturity of powertrain components and their contribution to potential powertrain improvements, in particular the reduction in emissions in relation to the penalties that may be imposed by authorities.

\subsection{Infrastructure Providers}

Powertrain options within the PTTMAM rely heavily on the provision of relevant and sufficient infrastructure and maintenance facilities, both of which are represented by the infrastructure provider group (green variables of Fig. 1). This is important, not just for the user, but also to the manufacturers who invest in new technologies. The main driver for the infrastructure provider to install new infrastructure is the return on investment that they will expect to receive for both new types of fuels at existing refuelling stations, and a new network of charging stations (both standard and fast-charging) for PiEVs. This investment, which has costs inversely proportional to cumulative installed infrastructure, can be supported by subsidies from authorities, and driven by fuel / power demand based on vehicle use by the users. In the PTTMAM, the infrastructure provider also is responsible for maintenance provision. One of the greatest influences on the remainder of the model, and of interest to the development of the EV market, is the effective available network (e.g. as charging posts are installed the proportion of households with access to charging is increased). This is more important for BEVs, which are fully reliant on charging, than PHEVs that are only partially reliant on the charging network.

\subsection{Authorities}

Authorities (grey variables of Fig. 1) have the power to influence all other market agents through their policies and incentives. In the PTTMAM they can be represented at either member state level or EU-wide, providing user fiscal incentives (e.g. subsidies, taxation, and scrappage schemes) and support to both manufacturer and infrastructure providers. The most important concept governed by the Authorities group are the fleet emission regulations. The model replicates the requirements of the actual regulations [2-5] and is an important driver for manufacturer investment in $R \& D$ of the powertrain components, which in turn drives improvements in the attributes as perceived by the user in the choice model.

\section{Method}

Previous publications utilising the PTTMAM have considered policy scenarios at an EU level with a long-term view. In this paper, the focus is turned to how responsive the model is in replicating "real-world" policy case studies and short term effects given the boundaries and assumption limitations. This demonstrates the flexibility of the PTTMAM and its suitability for policy design. It does not suggest that a single scenario should be taken as a forecast, more that scenarios can be compared to reveal policy implications. By carrying out this exercise, not only could insight into policy outcomes be obtained, but also an improved understanding of the model and methods to overcome challenges. In order to do this, two case study countries were chosen, Netherlands and UK. We iteratively test policy variables within the PTTMAM to determine a scenario that most closely represents (within the limitations of the model) the observed growth in sales of BEV and PHEV between 2011 and 2015, identifying the most appropriate scenario by visual data comparison with real world data. We do not imply that the resultant scenarios are accurate representations of the real world situation, simply an approximation for comparison. We then apply these scenarios across the EU and consider the specific cases of four other EU countries that have adopted contrasting policy approaches, in order to gain insight into the transferability of policies between 
member states. The Netherlands and the UK were chosen as two EU countries currently experiencing the greatest successes in EV uptake [21], but also because they have had diverse existing situations and adopted differing policy strategies to support EV. It is acknowledged that Norway could have made an interesting additional case study as it is the country with the highest take up and EV/capita in the world with a market share of $23 \%$ in 2015 [22]. However, the PTTMAM was initially designed to advise EU policy, affecting primarily only the $28 \mathrm{EU}$ member states of the EU, and so at present it is not possible to replicate Norway within the model. One important piece of legislation in this context is the Directive on the Deployment of Alternative Fuels Infrastructure (2014/94/EU) [6], which obliges the member states amongst others to establish national policy frameworks outlining their projections of future penetration of electric vehicles, corresponding infrastructure provision and support measures targeting vehicles and infrastructure deployment. Norway is not subject to this Directive. However, we do make comment on our findings in relation to Norway in the Discussion and Conclusion sections. Table 1 provides an overview of the variables adopted in the scenarios applied to the case studies, which are explained and justified in the following sections.

\section{Case Study 1: The Netherlands}

The Netherlands (NL) is currently the most successful EU member state in the uptake of EVs both in terms of growth and absolute numbers [21], with the sales of PiEV over the past 6 years shown in Table 2.

Similar to many EU countries with EV incentives in place, the main policies being employed in NL are exemptions for EVs from both registration ("BPM") and circulation ("MRB") taxes [24]. Such taxes are relatively high in NL compared to other states [19], at up to $€ 434$ per $\mathrm{gCO}_{2} / \mathrm{km}$ [25]. These exemptions have been in place since 2011, and were

Table 1 Comparison of variables considered in case study scenarios

\begin{tabular}{lll}
\hline Policy & Netherlands & United Kingdom \\
\hline Registration Tax Exemption & $\mathrm{X}$ & $\mathrm{X}(\mathrm{VED})$ \\
Circulation Tax Exemption & $\mathrm{X}$ & $\mathrm{X}(\mathrm{VED})$ \\
Registration Tax Demand Kick & $\mathrm{X}$ & $\mathrm{X}(\mathrm{VED})$ \\
Circulation Tax Demand Kick & $\mathrm{X}$ & $\mathrm{X}(\mathrm{VED})$ \\
Purchase subsidy & $\mathrm{X}$ & $\mathrm{X}$ \\
$\begin{array}{l}\text { Registration Tax considered in } \\
\text { purchase price rather than fixed costs }\end{array}$ & $\mathrm{X}$ & \\
$\begin{array}{l}\text { Congestion charge exemption } \\
\text { Charging installation subsidy }\end{array}$ & & $\mathrm{X}$ \\
\hline
\end{tabular}

originally due to end in 2014, but were later extended until 2017, with reductions for PHEV during 2016 [26]. There are also various policies that are difficult to directly capture in the PTTMAM, due to the current structure and scope. For example, favourable company car taxation allowances, subsidies for certain fleet vehicle types (€3-5000 for taxis and delivery vans) and regional/municipality incentives (such as infrastructure provision, additional purchase subsidies and free or priority parking) [26]. As the PTTMAM does not have a regional subscript below MS level nor detailed fleet taxation it was not possible to replicate these at this time. As the calibrated baseline used historical data to 2013, with limited PiEV data and no policies in place, an iterative method was followed to find a scenario that best fit reality, which focused on minor changes to the original base model and policy conditions. The resultant scenarios are described in the text below and in Table 3 . Resultant sales market shares from the scenarios and the actual data from Table 2 are then presented in Fig. 2 for BEV and Fig. 3 for PHEV.

Three amendments were made to the base model for this case study. Firstly, the original model only included tax reductions based on relative $\mathrm{CO}_{2}$ emissions, but for this study reductions/exemptions specifically for EVs were implemented. Secondly, the market share determined by the user group could be influenced by "demand kicks" from subsidies and exemptions. This demand kick is a calibrated multiplier of market share over the period that the incentive is in place, the value of which is determined by a sensitivity of a base demand kick to the magnitude of the subsidy/exemption. This characteristic did not originally include the circulation or registration tax exemption. Finally, scenarios were run where registration taxes were included in the purchase price of the vehicles, rather than the fixed operational costs as per the original model structure. As NL registration taxes are particularly high, and the exemption could have a bigger impact on the purchase decision, including registration taxes in the purchase price may be a more accurate account of reality. In addition to the above changes, an attempt was made to capture some of the idiosyncrasies of the incentives at regional or fleet level. As over $90 \%$ of EV purchases in 2014 were fleet vehicles [27], $€ 5000$ subsidies were implemented throughout the fleet. Furthermore, we tested the isolated impact of including only PHEV in the demand kick, as BEV results seemed to over-predict actual data.

Also worth mentioning, NL has had an extensive programme of installing public charging infrastructure [28] in addition to municipal initiatives and private charge point provision. This was difficult to implement in the current model structure where charging points are installed when they were predicted to satisfy a certain return on investment for infrastructure providers. Incorporation of exogenous policy-driven infrastructure provision will be considered in future versions of the model. For this study, even taking into account lower 
Table 2 Netherlands PiEV share of total passenger car sales and absolute numbers (2010-14 [23] adapted by [16]; 2015 [21])

\begin{tabular}{lllllll}
\hline & 2010 & 2011 & 2012 & 2013 & 2014 & 2015 \\
\hline BEV & $0.01 \%(53)$ & $0.15 \%(835)$ & $0.16 \%(806)$ & $0.62 \%(2,595)$ & $0.92 \%(3,558)$ & $0.71 \%(3,178)$ \\
PHEV & 0 & $0.002 \%(12)$ & $0.86 \%(4,728)$ & $4.70 \%(19,546)$ & $3.12 \%(12,021)$ & $8.96 \%(40,244)$ \\
\hline
\end{tabular}

predicted stock shares for EVs, installed public charge points in the model is at a level of around half of the actual numbers [26]. However, other studies using this model which have focused on infrastructure $[29,30]$ suggest, and correlate with other literature [31-33], that dense charge point provision has low importance to early EV adopters. It is noted that some studies are known to have placed stronger correlation between uptake and infrastructure [34-36], or at least acknowledge that concerns over recharging may deter EV purchase, but this is as much related to range and recharge time as infrastructure provision. However, little evidence was found to directly regard early adopters, so we retain our supposition that it is logical that they would be more reliant on private charging provision.

Looking at the results in Fig. 2, we can clearly see that NL 2 - NL 7 exhibit much higher sales growths than were realised up to 2012. As these are the scenarios which include a demand kick for BEV, it may be reasonable to assume that the additional attention paid to PHEV during this time caused a demand kick in sales of this model that did not occur in BEV. In particular, there were targeted promotions of models such as the Mitsubishi Outlander. In addition to the uncaptured policies, the lack of sales growth between 2011 and 12 that was observed in the real world data can be explained partly by the entry of PHEV into the market, creating competition between electric powertrains, when general concerns about the transition straight to BEV may have led to some consumers from discounting it from their decision set. Such issues led to higher sales (and thus higher overall exposure) of PHEV, and may have been sufficient for PHEV to pass a tipping point where the demand kick takes affect that the BEV did not achieve. Once these scenarios are discounted, we can focus on NL_Base, NL-1 and NL_8 - NL_15. Of these, only NL_14 and NL_15 exhibit reasonable approximations of the sales growth seen in 2013 and 2014, as well as a dip in sales in 2015. Again, these would all seem to be related to the interaction with the PHEV option not fully captured within the model. To overcome this in future work, an improved choice model, with a nesting structure allowing similar options to be considered more closely together, will be employed. Scenario NL_14, with registration taxes considered within the fixed costs (as in the default model), would seem to be marginally the better visual fit with the observed data.

For PHEV, the PTTMAM under predicts actual sales and growth rates in all scenarios, as well as failing to capture a dip

Table 3 Netherlands Scenario Conditions

\begin{tabular}{|c|c|c|c|c|}
\hline & $\begin{array}{l}\text { Registration and Circulation } \\
\text { Tax Exempt 2011-15 }\end{array}$ & $\begin{array}{l}\text { Registration and Circulation } \\
\text { Demand Kick }\end{array}$ & $\begin{array}{l}\text { Purchase Subsidy } \\
€ 5 \text { k 2013-14 }\end{array}$ & Registration Tax \\
\hline NL_Base & No & No & No & $\mathrm{FC}$ \\
\hline NL_1 & Yes & No & No & $\mathrm{FC}$ \\
\hline NL_2 & Yes & Yes & No & $\mathrm{FC}$ \\
\hline NL_3 & Yes & Registration only & No & $\mathrm{FC}$ \\
\hline NL_4 & Yes & Circulation only & No & $\mathrm{FC}$ \\
\hline NL_5 & Yes & Yes & No & PP \\
\hline NL_6 & Yes & Registration only & No & PP \\
\hline NL_7 & Yes & Circulation only & No & PP \\
\hline NL_8 & Yes & PHEV only & No & $\mathrm{FC}$ \\
\hline NL_9 & Yes & PHEV Registration only & No & $\mathrm{FC}$ \\
\hline NL_10 & Yes & PHEV Circulation only & No & $\mathrm{FC}$ \\
\hline NL_11 & Yes & PHEV only & No & PP \\
\hline NL_12 & Yes & PHEV Registration only & No & $\mathrm{PP}$ \\
\hline NL_13 & Yes & PHEV Circulation only & No & PP \\
\hline NL_14 & Yes & PHEV only & Yes & $\mathrm{FC}$ \\
\hline NL_15 & Yes & PHEV only & Yes & $\mathrm{PP}$ \\
\hline
\end{tabular}






Fig. 2 NL BEV sales shares under scenario conditions detailed in Table 3 and actual sales detailed in Table 2

in sales between 2013 and 2014. There are two real world phenomena not considered in the model that may explain the lower sales growth. Firstly, as already mentioned, over $90 \%$ of $\mathrm{EV}$ sales have been to fleet users rather than private customers. As the additional benefits provided to fleet customers from company car taxation relief is not currently captured in the PTTMAM structure, then the model may under predict the impacts of this, though fleet purchasers are considered to give greater weight to the costs in their purchase decision in the PTTMAM. Secondly, the PTTMAM does not capture regional offers such as subsidies and parking incentives. A third dynamic which could explain the uncaptured sales growth in both 2013 and 2015 is that in both of these years favourable EV tax conditions were due to end. In 2013, it was announced that PHEV benefits would be reduced in 2014, which may have led to a rapid growth in sales caused by customers that wanted to ensure that they would still benefit from the incentives. The expiry of the incentives was then delayed until 2016 which could maybe explain the second surge in 2015, and the lower sales of 2014. Advanced purchase decisions in the context of scrappage schemes or temporary incentives are a common phenomenon in the car market. Furthermore, as PHEV are not as reliant on the charging network as BEV, it may be that the impact of charging

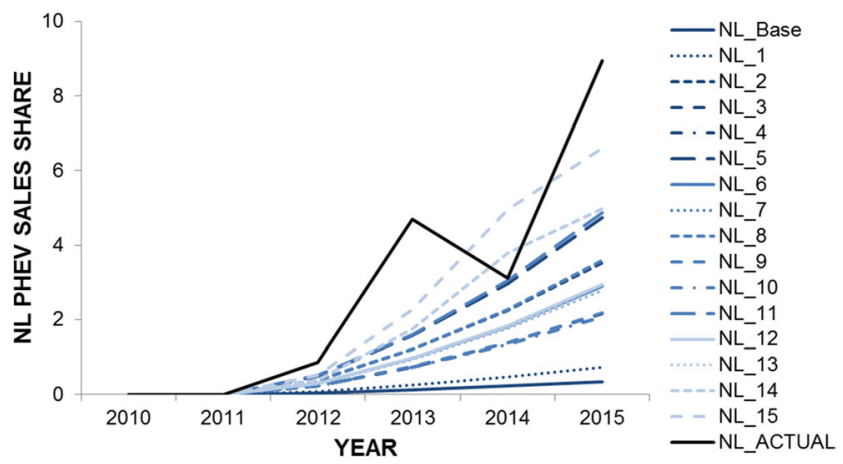

Fig. 3 NL PHEV sales shares under scenario conditions detailed in Table 3 and actual sales detailed in Table 2 availability on the convenience attribute is over-estimated. A final impact of 2015 may be the provision of favourable offers at the dealership level. For instance, the Mitsubishi Outlander, which was the highest selling model of 2015 [26], had offers available that could make the PHEV version less expensive that its conventional counterpart for some customers. Bearing in mind the above discussion and observations of the results Scenario NL 14 would seem to be an appropriate representation of the policy case in the Netherlands for this study, though should be considered conservative due to its smaller and more constant sales growth rates.

\section{Case Study 2: United Kingdom}

The United Kingdom (UK) is the third most successful EU country in terms of absolute numbers [21] and overall sales have at least doubled year-on-year since 2010, as presented in Table 4. It is clear that the UK lags somewhat behind the Netherlands, as presented in Table 2, particularly in terms of share, as the Netherlands has a smaller total volume of annual new registrations.

The UK has implemented various policies for EV uptake aimed at users, that have had many changes in recent years. The most prominent of these are the plug-in car grant, a $£ 5000$ subsidy(around $€ 6500$, limited to $25 \%$ of the vehicle purchase price), ${ }^{1}$ and an extensive ongoing infrastructure programme "Plugged-in Places" [37], involving eight test regions receiving investment for public infrastructure. In such places, not only is infrastructure being subsidised up to $75 \%$, but in many cases it is free to use and park. An assumption is made that it is a suitable approximation that EV users will seek out free parking opportunities. A $75 \%$ subsidy is also offered for the installation of home charging points. Vehicle Excise Duty (VED), the UK form of registration and circulation tax, is gradeated by tailpipe emissions, and vehicles emitting less than $100 \mathrm{~g} \mathrm{CO}_{2} / \mathrm{km}$ (which includes all BEV and most PHEV), have been exempt since 2010. From April 2017 these rates will change for all new cars, and only zero emission vehicles will be fully exempt from charges. ${ }^{2}$ There are also company car tax benefits available to fleet users. Furthermore, vehicles classed as a "green vehicle" (emitting below a certain amount) have been exempt from the City of London congestion zone fee from 2011. This was limited during 2013 to only

\footnotetext{
${ }^{1}$ In place since 2011 and recently amended to maximum $£ 4500 / 35 \%$, though this is outside the timeframe of the presented model https://www.gov.uk/plugin-car-van-grants (accessed 22/03/17)

${ }^{2}$ https://www.gov.uk/government/publications/vehicle-excise-duty/vehicleexcise-duty, accessed 07/04/17

${ }^{0}$ https://tfl.gov.uk/modes/driving/ultra-low-emission-zone, accessed 06/04/17

${ }^{0}$ This was estimated to be $€ 250$, based on 235 days a year (working days excluding holidays), an average $£ 10 /$ day over the time frame (The congestion charge was $£ 8 /$ day in 2010 , $£ 10$ /day from 2011 , and $£ 11.50$ /day from 2014 ) and affecting $10 \%$ of the UK fleet.
} 
Table 4 United Kingdom PiEV sales shares of total passenger cars and absolute numbers (2010-14 [23] adapted by [16]; 2015 [21])

\begin{tabular}{lclllll}
\hline & 2010 & 2011 & 2012 & 2013 & 2014 & 2015 \\
\hline BEV & $0.006 \%(116)$ & $0.056 \%(1088)$ & $0.064 \%(1298)$ & $0.111 \%(2496)$ & $0.271 \%(6688)$ & $0.377 \%(9934)$ \\
PHEV & $0(0)$ & $0.0004 \%(7)$ & $0.048 \%(985)$ & $0.043 \%(980)$ & $0.316 \%(7,805)$ & $0.712 \%(18,770)$ \\
\hline
\end{tabular}

"ultra-low emission vehicles" such as EVs. The zone is due to be augmented with an 'Ultra Low Emission Zone' by September $2020,^{3}$ that will enforce additional charges on vehicles not meeting exhaust emission standards, though this is beyond the scope of this study. Around $10 \%$ of UK vehicles are based in Greater London [38] and there has been a particularly strong EV uptake in the London commutable area [39]. As such it was felt appropriate to include this exemption in the scenarios, even though it is applied as a constant annual input across the whole UK fleet ${ }^{4}$ As it seemed that this exemption makes more of an impact on BEV than PHEV, scenarios were tested where only BEV benefited from the exemption. Shown in Table 5, various scenarios were designed, with the same baseline conditions as the NL case, and based on the above policies. Results and actual data are shown in Fig. 4 and Fig. 5.

For BEV, all scenarios other than the base would seem to have a close fit to the actual UK figures between 2010 and 2011. Scenario UK 3 has the closest correlation in the early years, though the remaining scenarios are somewhat lower (which may be explained by an under-estimated demand kick). Between 2011 and 2012, observed sales would seem to stagnate, which is not captured in any of our scenarios. One reason for this deviation could be similar to that discussed in the NL case, that the PTTMAM is not sophisticated enough at present to account for the introduction of the competitor powertrain PHEV in 2012. Though if this were the case then the model may under-predict in later years. Due to this stagnation however, the scenarios other than UK 3 and UK_Base have similar sales shares in 2012. Scenarios UK_1, UK_2, and UK_6 - UK _13, where PHEV do not have congestion charge exemption, display a very similar growth rate to the observed data between 2012 and 2013 whereas Scenarios UK 4-8 all marginally over predict due to the earlier impact of the congestion charge exemption. This has led to an observed sales share in 2013 that is between these two groups of scenarios. A strong growth rate between 2013 and 2014 has led to even higher sales than all of these scenarios, and is close to the sales that year captured in UK_3. Although growth rate of Scenarios UK_10-13 are closest to the observed during this period, they still under predict as the exemption impacts later in the time period, from 2014. Clearly there may be some

\footnotetext{
3 https://tfl.gov.uk/modes/driving/ultra-low-emission-zone, accessed 06/04/17

4 This was estimated to be $€ 250$, based on 235 days a year (working days excluding holidays), an average $£ 10$ /day over the time frame (The congestion charge was $£ 8 /$ day in $2010, £ 10$ /day from 2011 , and $£ 11.50$ /day from 2014 ) and affecting $10 \%$ of the UK fleet.
}

uncaptured behaviour or policy causing this. During the final period, 2014-15, the sales growth of all Scenarios UK 3-13 are similar to the observed growth, though with lower absolute sales due to earlier success in the observed data. The scenarios that include infrastructure subsidies and additional demand kicks make very little impact on the results. This is not surprizing. Firstly, as already observed in the discussion of the NL case, provision of public charging infrastructure would not be expected to have major impact on early uptake. Secondly, the home charging subsidy is a minor portion of the overall vehicle price (around 2\% of a c. $€ 40,000$ purchase). Finally, the demand kick from the taxes does not have the same impact as in the NL case as these taxes are a much smaller portion of the cost in the UK. Despite no direct match, based on these observations, scenarios UK _ 10-13 all show similar trends to the observed data that could be used to represent the real world.

As with the NL case, PHEV follows a different uptake path to BEV. All scenarios but Base and Scenario UK 3 have a reasonable correlation with the observed sales growth up to 2012, but fail to account for a sales stagnation in 2013. This would seem to be a trend also observed in BEV and NL case $\mathrm{BEV}$ - a fall or stagnation in the second year of sales. Although it was previously suggested that this may be due to the entry of PHEV, it may also be that there is a peak in the first year of sales as a new entry into the market, and the excitement is not sustained in the next year. There may of course be other explanations for this, such as an uncaptured uncertainty of policies or the actions of "early adopters" which are not currently captured in the PTTMAM as markets are not segmented. From 2013 to 2015, UK_3-5 and UK_9, which include a PHEV congestion charge exemption, seem to exhibit a similar growth trend to the observed data. The other scenarios (other than Base which has growth close to zero), all have rather lower sales growth rates than the observed data, though in 2014 the absolute sales are similar. This indicates that the congestion charge primarily stimulates BEV sales in reality. As with $\mathrm{BEV}$, infrastructure and demand kicks make little impact on PHEV uptake.

Shown in Fig. 4 and Fig. 5 the sales growth of both powertrains are generally under predicted by even the most similar scenarios, and this would seem to be explained by an uncaptured sales stagnation in the second year of sales. Similar to the NL case, it is likely partly due to the lack of detail on company car tax included in the PTTMAM, although private sales are a slightly higher portion of total sales in the 
Table 5 UK Scenario Conditions

\begin{tabular}{|c|c|c|c|c|c|c|}
\hline \multirow[b]{2}{*}{ UK_Base } & \multirow{2}{*}{$\begin{array}{l}\text { Purchase Subsidy } \\
£ 5 \text { k 2011-15 } \\
\text { No }\end{array}$} & \multirow{2}{*}{$\begin{array}{l}\text { VED Exemption } \\
2010-15 \\
\text { No }\end{array}$} & \multirow{2}{*}{$\begin{array}{l}\text { Congestion Tax Exemption } \\
\text { No }\end{array}$} & \multicolumn{2}{|c|}{$\begin{array}{l}75 \% \text { Charging Installation Subsidy } \\
\text { Public Home }\end{array}$} & \multirow{2}{*}{$\begin{array}{l}\text { VED Exemption } \\
\text { Demand Kick } \\
\text { No }\end{array}$} \\
\hline & & & & No & No & \\
\hline UK_1 & Yes & No & No & No & No & No \\
\hline UK_2 & Yes & Yes & No & No & No & No \\
\hline UK_3 & Yes & Yes & $2011-15$ & No & No & No \\
\hline UK_4 & Yes & Yes & 2013-15 & No & No & No \\
\hline UK_5 & Yes & Yes & $2013.5-15$ & No & No & No \\
\hline UK_6 & Yes & Yes & BEV only $2013.5-15$ & No & No & No \\
\hline UK_7 & Yes & Yes & BEV only $2013.5-15$ & $2013-15$ & $2010-15$ & No \\
\hline UK_8 & Yes & Yes & BEV only $2013.5-15$ & $2013-15$ & $2010-15$ & No \\
\hline UK_9 & Yes & Yes & $2014-15$ & $2013-15$ & $2010-15$ & No \\
\hline UK_10 & Yes & Yes & BEV only $2014-15$ & $2013-15$ & $2010-15$ & No \\
\hline UK_11 & Yes & Yes & BEV only 2014-15 & $2013-15$ & $2010-15$ & Yes \\
\hline UK_12 & Yes & Yes & BEV only $2014-15$ & $2013-15$ & $2010-15$ & Registration only \\
\hline UK_13 & Yes & Yes & BEV only 2014-15 & $2013-15$ & $2010-15$ & Circulation only \\
\hline
\end{tabular}

UK than NL. It is not certain what other uncaptured behaviours or policies the observations could be a result of, possibly unforeseen marketing, the introduction of new models (currently in the PTTMAM this is represented as a vehicle attribute from a simple function of the growing market share) or a change in public interest. However, based on the observations in growth trends relative to observed data discussed above, Scenario UK_11 has been chosen to represent UK EV policy.

\section{Country Comparison}

Following the successful replication of NL and UK policy case studies as described in the previous section, the next step of this study was to apply the designed scenarios to other countries in order to identify any further policy insights or model challenges. It is recognised that each member state has individual characteristics regarding its passenger car fleet


Fig. 4 UK BEV sales shares under scenario conditions detailed in Table 5 and actual sales detailed in Table 4 and market, including economic and social attributes. The scenario conditions were applied to every country in the EU. Due to inter-country feedbacks this will create a slightly magnified impact compared to applying the policy conditions to one country in isolation, as illustrated by the inclusion of the case study results for UK and NL in Fig. 6. Here it can be seen that the later years in the UK case are clearly more successful when the policies are applied EU wide, though this not so for NL. Although the UK case is essentially an extension of the NL case (which just had tax exemptions), it was felt useful to compare the two case studies to each other, to the whole EU and to individual countries, to elucidate policy insights as to not only what the tax exemptions could stimulate but also the additional UK policies.

As well as comparing NL and UK to each other and EU wide, focus was also given to four selected member states with differing current approaches to EV policy [24]. Denmark

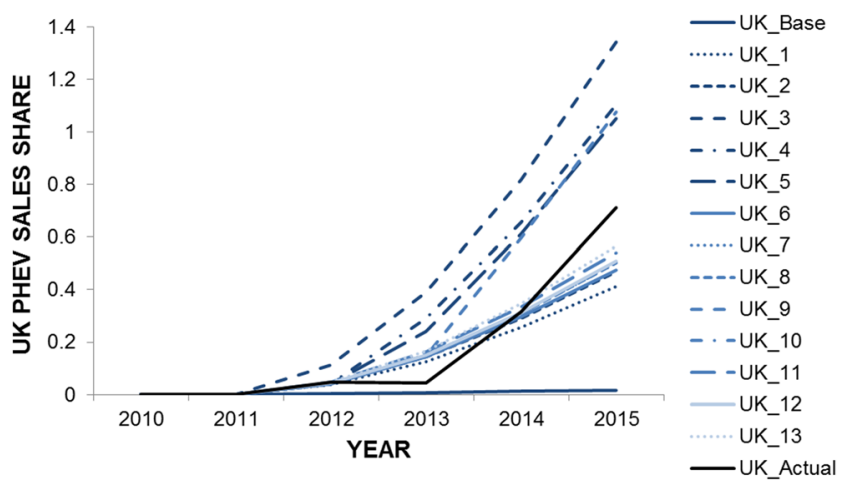

Fig. 5 UK PHEV sales shares under scenario conditions detailed in Table 5 and actual sales detailed in Table 4 
(DK) has higher rates of vehicle taxation than NL (up to $105 \%$ of vehicle value [25]), but less generous policies as only the registration tax is exempt; Germany (DE) is experiencing relatively successful sales despite few policy incentives being in place as only the low circulation tax is exempt; France (FR) has a unique "bonus-malus" scheme in place which is favourable towards BEV; and Luxembourg (LU) offered up to 2014 a $€ 5000$ purchase subsidy if the user obtained $100 \%$ renewable electricity [16]. The resultant sales shares in Fig. 6 are shown under both UK and NL cases and the real world data, and are discussed in the next section.

\section{Discussion}

In all circumstances, the UK policy case would produce better EV sales than the NL policy case, and in many this would have been better than sales that have been actually realised. This is not surprizing as the UK policy package includes the main NL policy (registration and circulation tax exemption), and all the illustrative countries were chosen because of their low take-up and/or policies. Due to differing existing market and policy conditions in each of the countries the results vary, and therefore some policy and modelling insights can be determined from the results.

Across the EU between 2012 and 2014, the model output suggests BEV sales could have been almost twice as successful had UK policies been in place. In 2015, BEV sales stagnated whereas under UK policy they could have doubled from 2014. EU PHEV sales would seem to be more in line with the PHEV oriented NL policies. However, if UK policies had been in place across the EU, which go further than NL as not only are tax exemptions offered but also additional incentives, then by 2015 sales could have been almost three times greater. Naturally, the EU actual sales mask the relative success (or failure) of each of the EU MSs, so attention now turns to the selected examples.

If the UK adopted only NL policies, without the additional policies to tax exemption, the UK would not have achieved more than a $0.1 \%$ sales share for either BEV or PHEV for any year in the period tested. This shows the importance of these additional measures in the UK to support EV uptake, as taxes are a relatively small portion of costs in the UK, compared to NL. For NL, had the additional UK policies been in place, then BEV sales could have been much greater. This would seem to reinforce the supposition that the NL policies were biased towards PHEV, something that was corrected by the NL with effect from 2016.

As previously remarked, Denmark has registration taxes even greater than NL, so BEV sales closely mirror the NL case in the early years, then following a stagnation between 2012 and 13 have a significant increase in sales in 2015 which actually makes them one of the most successful EU states for
BEV sales. ${ }^{5}$ This may partly be because Denmark announced during 2015 that they would be removing the tax exemption, and indeed the Tesla Model $\mathrm{S}$ was the biggest selling single model across all automobile sales in December 2015 [40]. However, had the full suite of UK policies been in place, this could have been even greater, yielding an almost $20 \%$ sales share, an unprecedented success. On the other hand, PHEV has witnessed very little success in Denmark as the tax exemption only applies to pure electric vehicles. Had it been in place, even in the absence of other polices similar to NL, then PHEV could have achieved in the region of an $8 \%$ sales share.

Perhaps one of our most striking results occurs in Germany, where the two case studies both yield lower sales for BEV than were achieved in reality until 2015, and the PHEV actual sales were better than the NL case but not the UK case. This would seem to suggest that there is some unique aspect to the automobile market in Germany that may not be captured currently in the PTTMAM. Germany has the biggest market in terms of car sales in the EU, as well as producing the highest number of cars [41]. Maybe due to these, German makes account for over $70 \%$ of domestic German sales [42]. As major manufacturers BMW and VW entered the EV market in recent years this may account for some of the unaccounted discrepancy. This said, Germany could have had around a doubling of 2015 sales had the UK policies been in place, and indeed the German government is currently considering the introduction of purchase subsidies [43], though possibly with a difference to other states as automobile manufacturers would be expected to contribute [44]. The NL case is not very successful in Germany as the registration and circulation taxes are very low.

France has had a "bonus-malus" scheme in place for a number of years that not only incentivises low emission vehicles but also deters the purchase of higher emission vehicles. In addition there are registration and company car tax exemptions available. Viewing the results obtained from the model, BEV sales have been more successful under these conditions than they would have been in the UK case, whereas PHEV would have benefited from UK policies being in place. This is a good illustration of how policies tailored to country specific needs or culture may be important.

The last country we considered was Luxembourg, a small country with high GDP and a renewables conditional EV purchase subsidy in place up until 2014 (the drop off in 2015 when this is removed can be seen). As such, either policy case would have resulted in more successful BEV and PHEV sales throughout the time period studied as they both offer greater benefits than that actually offered, though registration and circulation taxes are relatively low. This suggests that the model does behave as would be expected.

\footnotetext{
${ }^{5}$ Though it should be noted that the ACEA 2015 data did not distinguish between BEV and PHEV so they were all assigned to BEV in this study.
} 
Fig. 6 PiEV sales shares in the EU, case study countries (UK and NL) and selected comparative countries (DK. DE, FR, LU) under NL and UK policy scenarios determined in the case studies (NL_14 and UK 11) and actual sales (2010-14 [23] adapted by [16]; 2015 [21])
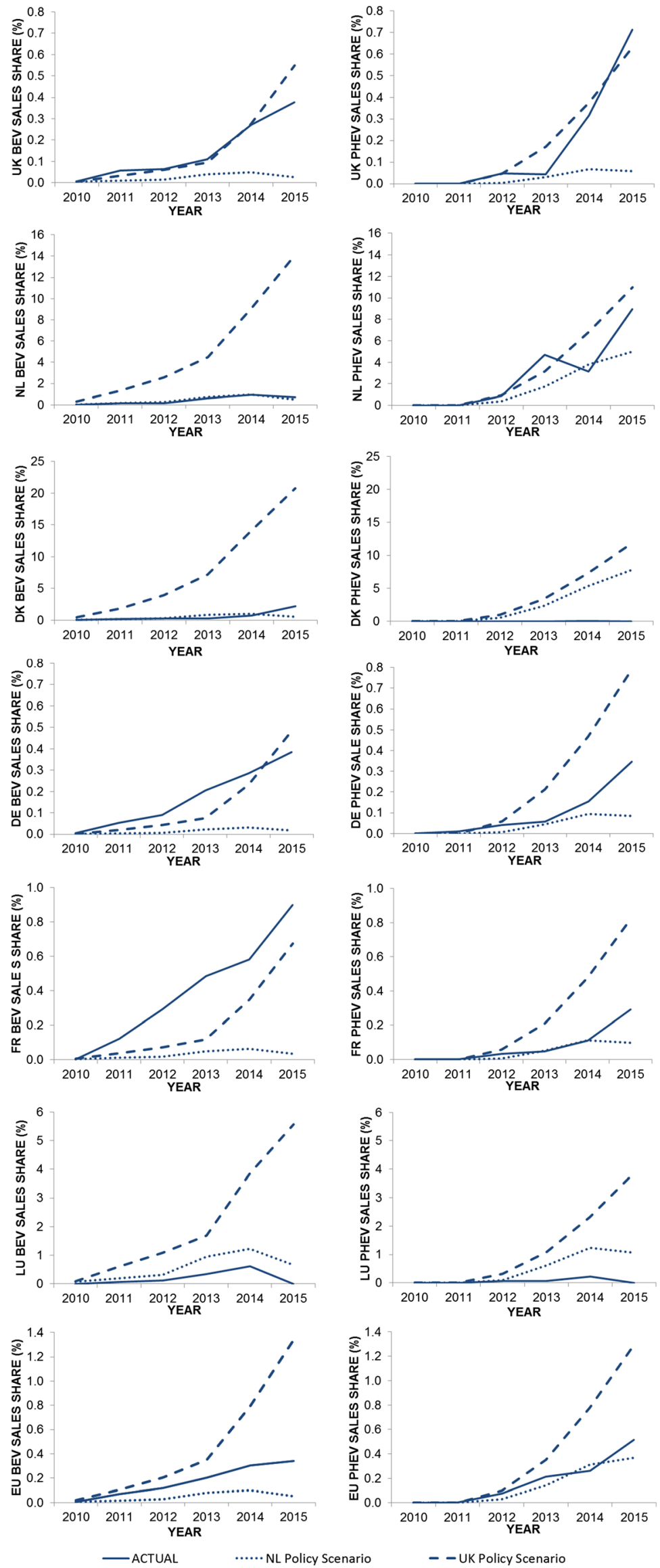
Although we were not able to actively model these scenarios against Norway as it was not explicitly included within the model, we can discuss our findings in the context of the Norwegian policies that led to it achieving the most successful EV uptake. Norway has had an extensive incentive programme since the 1990s, implementing the policies considered within our UK and NL scenarios, such as tax exemptions, congestion charging and network provision, as well as further support such as free use of parking, bus lanes, toll roads and ferries. These policies started to have a big impact from 2010 onwards, when the supply of electric vehicle models in the market increased $[45,46]$. Similar to NL, Norway has very high import/registration taxes meaning the exemption causes a significant attraction to EVs.

\section{Conclusions and highlights}

In this research paper we have addressed three research questions, and have been able to satisfactorily draw conclusions and insights from our findings, as highlighted in this section.

\subsection{Replicating short term effects of real world policies in individual countries}

Previous research focused on generalisations and long term applications of the model concentrating at the EU level. By successfully replicating approximations of the NL and UK policies and their success, this research suggests that the PTTMAM could be used to focus on more specific policies and country conditions. This helps to identify factors for success of each policy. For example the UK policy was found to produce more successful results in countries other than the UK, due to characteristics such as taxes, average costs and consumer preferences that may be more amenable to the policies than they were in the UK.

\subsection{Policy insights from EU countries experiencing EV success}

We conclude that while each EU member state has its own characteristics the PTTMAM can help in guiding policy design and facilitate learning across member states on which policies may work and which not.

- Even in countries with technology neutral policies, PHEV and BEV are likely to have very different uptake paths as they do offer different utilities to users. The model results seem to substantiate previous studies that early adopters are not reliant on a public charging infrastructure. There would appear to be an initial demand kick that should be factored into policy design, as should the impact of changing announcements to policies and their timing
- As demonstrated by the interaction between BEV and PHEV there is an important competition dynamic between electric powertrains at present, and so timing of the introduction of new models, and of targeted policies, is important as support for specific options may suppress the market development of others. This observation further supports the ongoing PTTMAM development towards a cross-nested choice model structure.

- Policies replicated in a different country will not produce the same results as policy success is sensitive to country specific conditions. This is despite the assumptions and generalisations necessary in any modelling exercise.

- The policy implications identified in this research can be transferred beyond the member states of the EU, even though they have not been directly modelled. The findings would appear to confirm that strong fiscal support is important, especially when high polluting vehicles are heavily taxed, as is the case with Norway. Although Norway has what can be undisputedly called EV success as almost a quarter of new sales in 2015 were PiEV, in the future the support policies may be reduced in recognition of an increased competitiveness of EV. This next stage of policy will be closely followed in order to inform future scenario development within the PTTMAM, in order to understand tipping points and how EV's become embedded into a decision set.

\subsection{Challenges to the use of modelling in policy appraisal.}

Although widely applied in transport research and policy appraisal it is acknowledged that any model is only a simplified representation of the real world, subject to boundaries, assumptions and interpretation. However, the choice of system dynamics as the underlying principle for the PTTMAM has advantages that may make it a more appropriate choice for policy appraisal than other options. For instance, the clear visualisation of logical feedback loops can be easily understood by non-modellers, facilitating dialogue on the model assumptions, as well as allowing a more open and engaging development process. These aspects may reduce subjectivity and mis-interpretation, and/or increase the confidence in the model by third parties. The validation tools available to the system dynamics modeller, such as extreme case testing and sensitivity analysis, coupled with short running times for even the most complex model, allows for an efficient calibration process and testing of many more scenarios than alternative modelling tools. Although there may be individual or nonempirical aspects that may be overlooked, subjective or difficult to capture, as long as these are clear to the parties designing scenarios, interpreting the results and applying them to policy decision making, modelling is an important and relevant part of a policy tool kit. 
AFV, Alternative Fuel Vehicle; BEV, Battery Electric Vehicle; DE, Germany; DK, Denmark; EU, European Union; EV, Electric Vehicle (BEV, PHEV + Fuel Cell Vehicle); FR, France; LU, Luxembourg; NL, The Netherlands; PHEV, Plugin Hybrid Electric Vehicle; PiEV, Plug-in Electric Vehicle $($ BEV + PHEV); PTTMAM, Powertrain Technology Transition Market Agent Model; R\&D, Research and Development; UK, The United Kingdom.

Open Access This article is distributed under the terms of the Creative Commons Attribution 4.0 International License (http:// creativecommons.org/licenses/by/4.0/), which permits unrestricted use, distribution, and reproduction in any medium, provided you give appropriate credit to the original author(s) and the source, provide a link to the Creative Commons license, and indicate if changes were made.

\section{References}

1. EU (2011) White Paper 2011: Roadmap to a Single European Transport Area - Towards a competitive and resource efficient transport system. European Commission

2. EU (2014) Regulation (EU) No 253/2014 of the European Parliament and of the Council amending Regulation (EU) No $510 / 2011$ to define the modalities for reaching the 2020 target to reduce $\mathrm{CO} 2$ emissions from new light commercial vehicles. European Commission

3. EU (2014) Regulation (EU) No. 333/2014 of the European Parliament and of the Council: Amending Regulation (EC) No. $443 / 2009$ to define the modalities for reaching the 2020 target to reduce $\mathrm{CO} 2$ emissions from new passenger cars. European Commission

4. EU (2011) Regulation 510/2011 of the European Parliament and of the Council setting emission performance standards for new light commercial vehicles as part of the Union's integrated approach to reduce $\mathrm{CO} 2$ emissions from light-duty vehicles. European Commission

5. EU (2009) Directive 2009/33/EC of the European Parliament and of the Council of 23 April 2009 on the promotion of clean and energy efficient road transport vehicles. European Commission

6. EU (2014) Directive 2014/94/EU of the European Parliament and of the Council of 22 October 2014 on the deployment of alternative fuels infrastructure. European Commission

7. Harrison G, Thiel C (2016) An exploratory policy analysis of electric vehicle sales competition and sensitivity to infrastructure in Europe. Technol Forecast Soc Chang 114: 165-178. doi:10.1016/ j.techfore.2016.08.007

8. Harrison G, Thiel C, Jones L (2016) Powertrain Technology Transition Market Agent Model (PTT-MAM): An Introduction. JRC Technical Report. European Commission, Luxembourg. doi: $10.2790 / 719385$

9. Pasaoglu G et al (2016) A systems dynamics based market agent model simulating future powertrain technology transition: Scenarios in the EU light duty vehicle road transport sector. Technol Forecast Soc Chang 104:133-146. doi:10.1016/j. techfore.2015.11.028

10. Harrison G, Shepherd SP (2014) An interdisciplinary study to explore impacts from policies for the introduction of low carbon vehicles. Transp Plan Technol 37(1):98-117. doi:10.1080/03081060. 2013.844904
11. Shepherd SP (2014) A review of system dynamics models applied in transportation. Transportmetrica B Transp Dyn 2(2):83-105. doi: $10.1080 / 21680566.2014 .916236$

12. Walther $\mathrm{G}$ et al (2010) Impact assessment in the automotive industry - mandatory market introduction of alternative powertrain technologies. Syst Dyn Rev 26(3):239-261. doi:10.1002/sdr.453

13. Struben J, Sterman JD (2008) Transition challenges for alternative fuel vehicle and transportation systems. Environ Plann B Plann Des 35(6):1070-1097. doi:10.1068/b33022t

14. Kwon T-H (2012) Strategic niche management of alternative fuel vehicles: A systems dynamics model of policy effect. Technol Forecast Soc Chang 79(9):1672-1680. doi:10.1016/j.techfore. 2012.05.015

15. Kohler $\mathbf{J}$ et al (2010) Infrastructure investment for a transition to hydrogen automobiles. Technol Forecast Soc Chang 77(8):12371248. doi:10.1016/j.techfore.2010.03.010

16. Thiel C, Krause J, Dilara P (2015) Electric vehicles in the EU from 2010-2014 - is full scale commercialisation near? Luxembourg, European Commission

17. EU (2016) Eurostat. Available from: http://ec.europa.eu/eurostat/ web/main/home. Accessed 28 June 2017

18. EC (2013) EU Energy, Transport and GHG Emissions.Trends to 2050. Reference Scenario 2013. European Commission

19. EMISIA (2013) TRACCS Project. Available from: http://traccs. emisia.com. Accessed 28th June 2017

20. Sterman JD (2000) Business Dynamics: Systems Thinking and Modelling for a Complex World. McGraw-Hill Higher Education, Boston

21. ACEA (2016) AFV Registration 2015. Brussels, European Association of Atuomobile Manufacturers

22. IEA (2016) Global EV Outlook: Beyond one million electric cars

23. EEA (2015) Monitoring of $\mathrm{CO} 2$ emissions from passenger cars Regulation 443/2009. Data Sets. 2010-2014. European Enviroment Agency

24. ACEA (2015) Overview of Purchase and Tax Incentives for Electric Vehicles in the EU in 2015. Brussels, European Automobile Manufacturers Association

25. ACEA (2015) ACEA Tax Guide 2015. Brussels, European Association of Automobile Manufacturers

26. RVO (2015) Electromobility in the Netherlands. Highlights 2014. Rijksdienst voor Ondernemend Nederland (Netherlands Enterprise Agency)

27. RVO (2015) Special: Analyse eigendom elektrische personenauto's. Rijksdienst voor Ondernemend Nederland (Netherlands Enterprise Agency)

28. ELaad (2016) ELaad NL. Available from: http://www.elaad.nl/ (in Dutch). Accessed 28 June 2017

29. Harrison G, Thiel C, Bolat P (2014) Model based analysis of policy options for E-mobility and related infrastructure in the EU, in Institution of Engineering and Technology 5th Hybrid and Electric Vehicle Conference. London, Institution of Engineering and Technology

30. Harrison G, Thiel C (2015) Comparing European member state electric vehicle uptake incentives and charging infrastrcture provision, in European Transport Conference 2015. Frankfurt, Association of European Transport

31. Bjerken KY, Norbech TE, Nordtomme ME (2016) Incentives for promoting Battery Electric Vehicle (BEV) adoption in Norway. Transp Res D 43(2016):169-180

32. Coffman M, Bernstein P, Wee S (2016) Electric vehicles revisited: a review of factors that affect adoption. Transp Rev :1-15. doi: 10.1080/01441647.2016.1217282

33. ElementEnergy (2016) Survey of consumer attitudes to plug-in vehicles. A report for the Department for Transport 
34. Li S et al (2016) The market for electric vehicles: Indirect network effects and policy design. Social Science Research Network. doi: $10.2139 /$ ssrn. 2515037

35. DfT (2015) Uptake of ultra low emission vehicles in the UK. A rapid evidence assessment for the Department for Transport. Lyndhurst B (ed). Available from: https://www.gov.uk/ government/publications/ultra-low-emission-vehicles-evidencereview-of-uptake-in-the-uk. Accessed 3 July 2017

36. Bühne J-A et al (2015) How to promote electromobility for European car drivers? Obstacles to overcome for a broad market penetration. Eur Transp Res Rev 7(3):1-9. doi:10.1007/s12544015-0178-0

37. OLEV (2013) Plugged-in Places. Available from: https://www.gov. uk/government/publications/plugged-in-places. Accessed 28 June 2017

38. DfT (2015) Vehicle Licensing Statistics: Data Table VEH0104Licensed vehicles by body type, by region and per head of population, United Kingdom, quarterly: 2015q1. Department for Transport, UK Government

39. DfT (2015) Vehicle Licensing Statistics 2014: Data Table VEH0130 Ultra-low emission vehicles (ULEV) licensed at the end of quarter, United Kingdom: 2010 q1 to 2015 q1. Department for Transport, UK Government

40. Lambert F (2015) Denmark's best selling car in December was for the first time an electric car: A Tesla Model S. Available from: http://electrek.co/2016/01/07/denmarks-best-selling-decemberelectric-car-tesla-model-s/ . Accessed 28 June 2017

41. ACEA (2015) The Automobile Industry. Pocket Guide 2015--16. European Automobile Manufacturers Association, Brussels

42. VDA (2016) Market Germany. Available from: https://www.vda. de/en/topics/automotive-industry-and-markets/german-market/ development-of-the-german-market.html. Accessed 28 June 2017

43. Ayre J (2016) Germany Considering $€ 5,000$ Electric Car Subsidy, With Automakers Contributing 40\%. Available from: http:// cleantechnica.com/2016/03/01/germany-implementing-e5000electric-car-subsidy-with-automakers-contributing-40/. Accessed 28 June 2017

44. Autobild (2016) Der Bund wird sich beteiligen (in German). Available from: http://www.autobild.de/artikel/regierungsplaenekaufanreiz-fuer-elektroautos-8535657.html. Accessed 28 June 2017

45. Figenbaum E et al (2015) Increasing the competitiveness of evehicles in Europe. Eur Transp Res Rev 7(3):28. doi:10.1007/ s12544-015-0177-1

46. Lévay PZ, Drossinos Y, Thiel C (2017) The effect of fiscal incentives on market penetration of electric vehicles: A pairwise comparison of total cost of ownership. Energy Policy 105:524-533. doi:10. 1016/j.enpol.2017.02.054 